\title{
Estudo da Adaptação Fetal ao Sofrimento Crônico: Avaliação Dopplerfluxométrica, Hematimétrica e
} Metabólica

Autor: Henrique Vitor Leite

Orientador: Prof ${ }^{\circ}$. Dr. Antônio Carlos Vieira Cabral

Tese apresentada ao Departamento de Ginecologia e Obstetrícia da Faculdade de Medicina da Universidade Federal de Minas Gerais, como requisito parcial para obtenção do grau de Doutor, em 20/12/98.

Estudo longitudinal, prospectivo em que foram acompanhadas 128 pacientes com feto único, portadoras de algum fator de risco para o sofrimento crônico, encaminhadas do pré-natal de alto-risco e medicina fetal do Hospital das Clinicas da UFMG de junho de 1995 a maio de 1998, cuja idade gestacional no momento do parto variou entre 29 e 41 semanas. O objetivo do presente estudo foi avaliar os mecanismos de adaptação fetal ao sofrimento crônico (centralização de fluxo, aumento do número de eritroblastos e metabolismo anaeróbio) em face de alterações gasométricas (acidose, hipóxia e hipercapnia). Em todas as pacientes realizou-se dopplerfluxometria de artéria umbilical e cerebral média calculando o índice de pulsatilidade (IP) e a seguir o índice umbílico/ cerebral (U/C). Considerou-se como centralização de fluxo quando o U/C foi maior ou igual a 1 (um). Após a interrupção da gestação por via abdominal e sob bloqueio peridural ou raquianestesia, foi colhido sangue na veia umbilical e realizada a avaliação gasométrica (dosagem do $\mathrm{pH}, \mathrm{pO}_{2}, \mathrm{pCO}_{2}$ e $\mathrm{BE}$ ), dosagem da glicemia fetal e do número de eritroblastos. Foi de determinada a glicemia materna e a diferença entre esta e a fetal ( $\Delta$-glicêmico), definido como alterado quando $>$ ou igual a $18 \mathrm{mg} / \mathrm{dl}$. O número de eritroblastos foi considerado alterado quando $>$ ou igual a 7/100 leucócitos. Foi realizado um cruzamento dos resultados da gasometria em relação à centralização de fluxo, eritroblastose e $\Delta$-glicêmico materno/fetal. Encontramos que a centralização de fluxo é um dos primeiros mecanismos de adaptação fetal ao sofrimento crônico. Fetos acidóticos graves, com $\mathrm{BE}<-12 \mathrm{mmol} / 1$ apresentam ambas as respostas adaptativas. O $\Delta$-glicêmico materno fetal não se mostrou parâmetro de adaptação, mas sim, marcador da conseqüência do sofrimento crônico.

Palavras-chave: Dopplerfluxometria. Centralização de fluxo. Sofrimento fetal.

\section{Perfil Epidemiológico da Natimortalidade em Caxias do Sul}

Autor: Dino Roberto Soares De Lorenzi

Orientadora: Prof ${ }^{\mathrm{a}}$. Dr ${ }^{\mathrm{a}}$. Ana Cristina D'Andretta Tanaka

Dissertação apresentada ao Departamento de Saúde Materno-Infantil da Faculdade de Saúde Pública da Universidade de São Paulo para obtenção de Título de Mestre, em 28/01/99.

Objetivos: Estudar os casos de natimortalidade verificados em uma população cliente do Sistema Único de Saúde (SUS), correlacionando os resultados obtidos com as condições de assistência perinatal prestadas. Material e Método: Estudo descritivo de 78 casos de natimortalidade ocorridos entre gestantes do SUS no municipio de Caxias do Sul/RS entre janeiro de 1996 e dezembro de 1997.

Resultados: Os coeficientes de natimortalidade foram de 12,5 e 14,7 por mil nascimentos para os anos de 1996 e 1997, respectivamente. O risco relativo (RR) de natimortalidade mostrou-se maior entre as gestantes do SUS em relação às gestantes oriundas da clínica privada $(R R=1,49)$. Constatou-se predominio de natimortos com menos de 37 semanas de gestação $(64,7 \%)$ e peso ao nascer inferior a $2500 \mathrm{~g}(65,7 \%)$, o qual em $65,4 \%$ dos casos era adequado à idade gestacional. A maioria das perdas fetais $(79,5 \%)$ ocorreu antes da internação hospitalar, sendo a causa mais freqüente de óbito a síndrome hipertensiva $(15,5 \%)$, enquanto que o percentual de causas indeterminadas foi de $19,2 \%$. Cerca de $74,7 \%$ das gestantes fez prénatal, entretanto em $56,2 \%$ dos casos este foi considerado inadequado em função do número de consultas realizadas ser insuficiente em relação à idade gestacional em que ocorreu o óbito.

Conclusões: A utilização do estudo da natimortalidade como indicador de saúde constatou a necessidade de se revisar a atenção pré-natal oferecida às gestantes pelo SUS no município de Caxias do Sul, enfatizando principalmente os seus aspectos qualitativos, a fim de se obterem melhores resultados perinatais.

Palavras-chave: Natimortalidade. Natimorto. Óbito fetal. 